\title{
Reinventando a vida: um estudo qualitativo sobre os significados culturais atribuídos à reconstrução corporal de amputados mediante a protetização
}

Luciana Laureano Paiva ${ }^{1}$

Silvana Vilodre Goellner ${ }^{2}$

PAIVA, L.L.; GOELLNER, S.V. Reinventing life: a qualitative study on the cultural meanings attributed by amputees to body reconstruction through implantation of prosthetics. Interface - Comunic., Saúde, Educ., v.12, n.26, p.485-97, jul./set. 2008.

The cultural meanings that amputees attribute to their bodies and their daily lives following the use of prosthetics were analyzed. Cultural and sociohistorical studies on the human body were used as theoretical presuppositions. Nine patients (six men and three women) aged 18 to 82 years participated in the study, along with a prosthetician and a physical therapist. The interviews were analyzed using the content analysis technique, and four thematic categories were identified: "Becoming different: the amputated body"; "Getting accustomed to a different body"; "Imperfection as seen by others"; "The prosthetized body: another version of oneself". Analysis according to categories revealed that prostheses were seen as a way of recovering body aesthetics as well as lost functions, such that the patients came to see their bodies as whole again. Using a prosthesis signified a way to remain human, even if sustained by an artificial object.

Key words: Amputees. Artificial limbs. Bodily reconstruction.
Analisaram-se os significados culturais que os indivíduos amputados atribuem aos seus corpos e às suas vidas cotidianas após uso de prótese. Foram utilizados, como pressupostos teóricos, os estudos culturais e sóciohistóricos sobre o corpo humano. Participaram da pesquisa nove pacientes, sendo seis homens e três mulheres, com idades variando de 18 a 82 anos, além do protesista e do fisioterapeuta. As entrevistas foram analisadas por meio da técnica de análise de conteúdo, sendo identificadas quatro categorias temáticas: "Tornar-se outro: o corpo amputado"; "Familiarizar-se com um outro corpo"; "A imperfeição vista pelos outros" e "O corpo protetizado: um outro de si mesmo". A análise por categorias revelou que a prótese foi observada como uma forma de resgatar a funcionalidade perdida e também a estética corporal na medida em que os pacientes viram seus corpos novamente como completos. O uso da prótese significou uma forma de manter-se humano mesmo que sustentado por um objeto artificial.

Palavras-chave: Amputados. Membros artificiais. Reconstrução corporal.

Sivana Vilodre Goelher

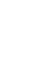




\section{Introdução}

No transcorrer dos tempos, o corpo humano, por si só, não sofreu grandes transformações em sua matriz biológica, mas sua materialidade foi significada pelas sociedades de diferentes formas, tendo como referências costumes, valores estéticos e morais. Inúmeras verdades e diferentes concepções foram e estão sendo construídas a seu respeito, no decorrer de sua história. Isso significa afirmar que os saberes construídos sobre o corpo humano são provisórios e contextualizados num dado momento histórico.

Não há dúvidas de que, na sociedade ocidental contemporânea, o corpo passou a ser visto como um artefato ${ }^{3}$ de presença que ostenta a identidade dos sujeitos. A aparência corporal, além de ser uma presença inscrita no biológico do corpo, carrega consigo significados que são culturalmente construídos (Sant'anna, 2001). Nesse sentido, algumas marcas corporais são significadas como sinais de beleza, de saúde e de perfeição, enquanto outras carregam consigo o estigma de serem vistas como sinal de feiúra, de doença ou de deficiência (Tucherman, 1999; Sfez, 1996).

Marcadas pela falta de um membro ou segmento corporal, as pessoas amputadas trazem inscritos em seus corpos sinais que as identificam como sendo diferentes, não raras vezes, sendo identificadas também como seres imperfeitos e incapazes. No Brasil não há estatística precisa sobre o número de amputações realizadas anualmente, porém aproximadamente $85 \%$ delas ocorrem em membros inferiores (Luccia, 2001).

Como afirma Omote (1997), apesar de sabermos que são infindáveis as diferenças entre as pessoas, algumas características corporais destacam-se mais que outras, como, por exemplo, as marcas da amputação, as quais são atribuídas como uma diferença desvantajosa entre os indivíduos, podendo levar a um descrédito socialmente construído.

Considerando as adversidades encontradas pelas pessoas submetidas a amputação de um membro corporal na sociedade brasileira, este estudo buscou compreender os sentimentos presentes, as emoções e os significados atribuídos por essas pessoas à transformação corporal vivenciada. Mais especificamente, procurou desvelar o processo de amputação e protetização, sob a perspectiva das pessoas que as vivenciaram, questionando seus estigmas, suas mortes reais e simbólicas, e os efeitos provocados pela hibridização com as próteses.

Caracteriza-se, portanto, por ser uma investigação de cunho qualitativo, cujo trabalho empírico foi desenvolvido com os pacientes que freqüentavam uma clínica privada situada na cidade de Porto Alegre (RS), com atuação especializada na reabilitação e protetização de pessoas submetidas à amputação. A delimitação do grupo a ser investigado também constitui uma etapa relevante do caminho investigativo (Spink, 2000). Este foi selecionado de forma intencional, e o principal critério de seleção foi ser portador de uma amputação adquirida, por meio de intervenção cirúrgica, tendo em vista que algumas pessoas já nascem com a ausência (agenesia) de membros, além de estarem em processo de adaptação à prótese, ou serem usuários recentes da mesma.

Participaram desse estudo nove pacientes, sendo seis homens e três mulheres, com idades variando de 18 a 82 anos, além do protesista e do fisioterapeuta da clínica. Os participantes se dispuseram a colaborar com a pesquisa mediante a assinatura do Termo de Consentimento Livre e Informado, e seus nomes foram alterados objetivando preservar as suas identidades.

A pesquisa de campo foi desenvolvida ao longo do ano de 2004, tendo, como instrumentos de coleta de informações, as entrevistas semi-estruturadas individuais

\author{
3 Para Bourg (1996), os \\ artefatos são "objetos \\ técnicos que nós \\ fabricamos" ou "objetos \\ naturais que nós \\ modificamos". Neste \\ sentido, no texto, \\ artefato significa de \\ forma metafórica o \\ "objeto corpo" \\ modificado \\ constantemente pelo \\ próprio homem, seja \\ pelas vestimentas que \\ usa, os acessórios que \\ carrega, pelos músculos \\ que ostenta etc., \\ construindo \\ pertencimentos
}


e a observação participante, ambas realizadas no decorrer de encontros mensais efetuados com os pacientes amputados, amigos e familiares, durante e após as sessões de fisioterapia e ajustes da prótese.

Todos esses momentos foram registrados nos cadernos de campo e tornaram-se fundamentais para a aproximação com os participantes da pesquisa, pois se mostraram como espaços privilegiados para agendar as entrevistas, conhecer suas rotinas da clínica e suas percepções a respeito do processo de protetização. As entrevistas foram gravadas em fita microcassete, tendo uma duração que variou entre vinte minutos a uma hora.

A opção pela realização de entrevista semi-estruturada objetivava conferir maior liberdade ao participante para narrar suas experiências individuais. Os eixos norteadores das entrevistas foram compostos pelos seguintes temas: o significado do corpo para si, tornar-se um amputado, o olhar do outro e o processo de protetização. O uso da entrevista como um instrumento privilegiado na coleta das informações partiu da compreensão de que os participantes da pesquisa são pessoas ativas no processo de produção de sentidos. Desta maneira, pode-se afirmar que a interação não inclui apenas alguém que fala e um outro que ouve, mas todos os outros que ainda falam, que ainda ouvem ou que, imaginariamente, poderão falar ou ouvir. Sob esse ângulo, muitas vozes se fizeram ouvir durante as entrevistas, incluindo interlocutores presentes e ausentes (Pinheiro, 2000; Spink, 2000).

As narrativas dos participantes do estudo foram analisadas por meio da técnica de Análise de Conteúdo (Bardin, 1977), tendo como base os pressupostos teóricos dos estudos culturais e sociohistóricos sobre o corpo (Couto, 2000; Johnson, 1999; Bourg, 1996). Com base nesta triangulação entre a revisão teórica e as narrativas, foram construídas quatro categorias temáticas: "Tornar-se outro: 0 corpo amputado"; "Familiarizar-se com um outro corpo"; "A imperfeição vista pelos outros" e "O corpo protetizado: um outro de si mesmo".

\section{Tornar-se outro: o corpo amputado}

O processo de construção do conhecimento do sujeito passa, necessariamente, pelo seu corpo, uma vez que nossa existência é corporal (Le Breton, 2006). A subjetividade se constrói com o corpo por meio: de seus prazeres e sofrimentos, de suas qualidades e eficiências, de seus defeitos, do que ele já foi, do que já está deixando de ser, de como gostaríamos que um dia fosse, das formas pelas quais o exercitamos, das técnicas de controle que exercemos sobre ele, dos nossos anseios, da sua finitude e, paradoxalmente, do receio que sentimos diante da possibilidade de um dia se tornar um estranho para nós mesmos.

Durante as entrevistas, esse receio se tornou bastante evidente. Não foram poucas as vezes em que os participantes da pesquisa relataram que falar de seus corpos amputados era uma tarefa difícil, pois ao nomeá-los, de certa forma, estavam tornando-os mais visíveis, especialmente nas suas diferenças e imperfeições. Por esta razão, nas entrevistas, seguidamente se reportavam ao passado, a um período que antecedia à amputação, onde seus corpos ainda eram identificados como "perfeitos" e "saudáveis", consoante os padrões estéticos vigentes na sociedade contemporânea: "Antes da minha amputação, do meu acidente, eu tinha uma vida como um jovem normal. Eu praticava esportes, eu gostava de dançar. Mas agora, com isso, ultimamente eu nem entrei mais na água. Jogar futebol, nadar, dançar, era bom" (Rogério, 18a).

A condição de amputado era narrada como integrante de um modo de vida "anormal", pois já não conseguiam mais se enquadrar nos padrões naturalizados como pertencentes à "normalidade". Muitos deles afirmavam terem perdido não somente uma parte de seus corpos, mas, junto com ela, a vida que levavam, a saúde que tinham e a sua eficiência corporal. Por certo que, em uma sociedade que privilegia a performance e o dinamismo, "perder" uma perna significa deixar perder "força, rigidez, juventude, longevidade, saúde, beleza [...] critérios que avaliam o valor da pessoa e condicionam suas ações" (Ortega, 2002, p.157). Em decorrência dessa percepção, vários entrevistados mencionaram a necessidade de cuidar dos seus corpos com o intuito de salvá-los diariamente, ou ainda, de salvar aquilo que dele ainda permanece: "Eu valorizo bastante agora, todo o resto que eu tenho. Não quero perder mais nada. E agora, ando me cuidando mais" (Rogério, 18a). 
Dou muita importância porque ainda sobrou um pedacinho da perna que dá pra botar uma prótese. Mais uma vez prova de que o corpo, uma parte do corpo que ficou é muito importante. Faz muita falta pra gente e pra tudo! (Juliano, 76a)

Os cuidados com o corpo foram intensificados após a amputação. Paulatinamente, os participantes tiveram de reaprender a dominar seus corpos renunciando à gratificação imediata de seus desejos mais simples, como ficar em pé novamente sem precisar das muletas. Esse controle sobre seus corpos não se deu sem o despontar de uma série de sentimentos ambíguos: amor e ódio, desejo e repulsão, cuidado e descuido pelo próprio corpo. Suportar esses sentimentos e superar as dores reais e simbólicas atreladas ao processo de amputação foram observadas como uma maneira de resistir à morte, pois alguns passaram pela experiência do coma. Todos mencionaram quanto foi difícil aceitar a cirurgia de amputação, pois, para além do dano físico, tiveram de romper com o seu cotidiano, abdicando, muitas vezes, da presença da família e dos amigos no esforço de salvar seu corpo da degenerescência, ficando, por exemplo, mais de um ano no hospital, na tentativa de reverter uma infecção na perna.

Para os participantes, sua saúde dependia, em grande medida, da reposição da peça desgastada, ou seja, do segmento que já não funcionava adequadamente e que teve de ser extirpado por via cirúrgica. A essa representação mecânica do corpo corresponde, também, a percepção de que sua perfeição está na inteireza e que a incompletude é sinônimo de imperfeição (Sfez,1996).

É aquela velha história. Quando a gente 'tá' todo perfeito, a gente não dá bola. Depois que perde, começa a pensar como era importante aquilo pra gente. Eu acho que as pessoas têm as duas pernas e os braços, vivem reclamando da sua aparência, ou vivem reclamando da vida. (Rogério,18a)

Afinal, como afirma Canguilhem (2000), "ser doente" não significa somente passar a viver uma vida diferente, porque o conceito de doença também está atrelado a um julgamento de valor, "estar doente" significa, da mesma forma, tornar-se alguém nocivo, indesejável ou socialmente desvalorizado.

Diante de tal representação, os participantes consideravam que seus corpos passaram a ser imperfeitos após a amputação, e que esta incompletude precisava ser "preenchida" com o uso das próteses. Segundo Omote (1997), apesar de sabermos que são infindáveis as diferenças entre as pessoas, algumas características corporais destacam-se mais que outras, como, por exemplo, as marcas da amputação, as quais são atribuídas como uma diferença desvantajosa entre os indivíduos, podendo levar a um descrédito socialmente construído.

A condição de amputado remete a um estilo de vida diferenciado, onde os sujeitos já não conseguem mais se enquadrar nos padrões de normalidade valorizados pela sociedade contemporânea. Perdem, assim, não somente uma parte de seus corpos, mas junto com ela a vida "normal" que levavam, a saúde que tinham e a eficiência corporal. Nas suas falas é possível identificar que o corpo é observado como o principal ponto de referência que sustenta a definição de quem se enquadra ou não em um padrão de saúde e de "normalidade". O corpo amputado revela, desta forma, um passado que passa a ser presentificado a todo momento.

Nesse sentido, a possibilidade de protetização adquire um caráter bastante singular, uma vez que reconstrói o corpo de forma que o sujeito apropria-se dele novamente, voltando a ser visto como alguém "saudável". Distanciando-se da representação de ser "doente", este corpo, ainda que reconstruído artificialmente, adquire nova visibilidade e valorização: "O significado do corpo é o mesmo que uma máquina. Se estragar uma peça pára, emperra. Ou tira e para botar outra, às vezes, não funciona. E o corpo completo é uma coisa óbvia, fundamental. Não se pode desprezar nunca. É muito diferente, muito!" (Juliano,76a).

De acordo com Le Breton (1995), a condição do ser humano é corporal, pois é seu corpo que o separa do Outro, que o individualiza, aquilo que estabelece a fronteira da sua identidade pessoal. Se o ser humano não existe senão por meio de suas formas corporais, que o colocam no mundo, toda modificação de sua forma faz com que uma outra definição de sua humanidade seja construída. Isso significa que subtrair dele uma parte, como no caso da amputação, ou acrescentar alguma coisa como, 
por exemplo, uma prótese, faz com que o indivíduo seja colocado numa posição ambígua, intermediária, afetando simbolicamente o seu vínculo social.

Portanto, para os participantes do estudo, realizar uma amputação remete a um outro momento de suas vidas, que vem a ser reconstruir os modos de ver a si próprio, num primeiro momento, aprendendo a conviver com a incompletude. Ao optarem pela protetização, foram em busca de uma outra configuração corporal que, mesmo artificial, carrega em si os signos da completude. Processo esse vivido de forma particular, evidenciando, sobretudo, que, para cada um, o que vem a ser um corpo "perfeito" não é algo estanque, mas que está diretamente relacionado à sua história de vida, que é unívoca e intransferível.

\section{Familiarizar-se com um outro corpo}

Para os participantes do estudo, a amputação foi identificada como um processo doloroso e inesperado: uma casualidade. Algo que escapou ao controle e que rompeu com o vetor linear do tempo histórico, do esperado, do que seria o "natural". O corpo amputado foi narrado como um campo de batalha que, ao ser exposto ao olhar do outro, foi desvelado na sua deficiência: um lugar no qual os acontecimentos concretos foram escritos e inscritos como cicatrizes, como alfabeto de dor e sofrimento (Pombo, 2002; Vilela, 2001).

A história que vinha sendo construída até o momento da amputação fica interrompida, chega ao fim, pois o indivíduo passa a narrar sua história de vida em dois momentos distintos, ou seja, antes da amputação e depois da amputação. O corpo amputado revela um passado que passa a ser presentificado a todo momento. Revela, também, a morte real de uma parte do corpo, bem como a morte simbólica de um estilo de vida, de uma forma de ser e de uma identidade, ainda que compreendam que optar pela "morte" de uma parte significa, no seu caso, dar vida a todo o restante. Nessa perspectiva, o "fazer viver" tornou-se um imperativo, mesmo que para isso o indivíduo tivesse de abdicar de uma parte de si, de um modo de vida para reviver numa outra "forma" corporal.

Em relação à amputação, foi muito difícil. Tu vês, tanto é que durante seis anos eu tentei manter a minha perna. Ela tava toda danificada, tava feia, tava enorme [...[ Mas, mesmo assim, era a minha perna. Eu tinha vontade de manter ela. Fiz doze cirurgias na perna. Eu só não a mantive porque chegou um momento em que eu tive que optar entre a perna ou a minha vida. Se eu não amputasse a perna, eu ia morrer. Então, eu tive que amputar. Foi uma decisão muito difícil. (Júlia, 49a)

Conforme afirma Villaça (1998), os indivíduos atribuem a partes de seu corpo, como por exemplo o sangue, o esperma e o coração, uma carga parcial ou total de sua identidade. Portanto, amputar uma perna pode significar a perda de uma referência, da identificação com relação ao outro, pois o seu corpo "diferente" não serve mais como um parâmetro de igualdade.

Nas narrativas dos participantes, percebe-se que, após a amputação, eles viam seus corpos como sendo algo ao mesmo tempo desconcertante e desconhecido, pois sua configuração corporal já não obedecia a qualquer modelo de racionalidade predominante, na medida em que os padrões corporais tidos como normais, tornam-se inviáveis como modelos de semelhança e identificação. O corpo amputado escapa de possíveis enquadramentos, confirma a todo instante ou explicita a diferença, caráter indisfarçável de "eterno estrangeiro" aos olhos dos outros.

De acordo com Kristeva (1994), a estranheza e a alteridade podem ser pensadas sob diferentes perspectivas. O estrangeiro pode ser um vizinho calado, aquele que não é do nosso time, partido, grupo, turma, não importa. Na verdade, a condição de estrangeiro é dada por qualquer um diferente de nós mesmos, ou seja, o Outro. Neste sentido, pode-se pensar que o corpo que passou por um processo de amputação "torna-se um estrangeiro", pois os seus atributos, até então familiares, foram extirpados juntamente com o segmento que perdeu. O corpo amputado é aquele que vive na ambigüidade de um dia ter sido um corpo "completo" em sua materialidade orgânica e que, abruptamente, é posicionado no lugar da diferença, da alteridade, tornado um estranho para o Outro e para si mesmo. 
Nesse sentido, a amputação provoca uma modificação permanente na aparência do indivíduo, em sua auto-imagem, suscitando sentimentos perturbadores, como mostram os seguintes depoimentos:

\begin{abstract}
Até então, eu não me aceitava muito bem. Não me aceitava mesmo. Não aceitava minha aparência. Quando eu sonhava, eu sonhava que eu era perfeito. Nunca sonhava com essa situação. (Guilherme, 36a)
\end{abstract}

Eu envelheci uns 10 anos... Eu sempre tava de bem com a vida. Eu gostava muito de fazer as coisas diferentes, sabe. Agora, mal dá pra mim defender o necessário [...] Antes eu valorizava muito o meu corpo. Antes, né. Mas, depois que aconteceu isso aqui, nada tem mais valor para mim [...] Já faz tempo e assim, não posso me acostumar [...] Ah! Meu Deus! Coisa feia faltar um pedaço da gente. Que coisa horrível! Eu acho horrível! (Paula, 65a)

O paradoxo do corpo, para Gil (2002), está no fato de ele ser articulável num todo orgânico, onde cada membro que o constitui guarda sua autonomia, seguindo direções próprias. Essa característica, de fato, é que permite que o corpo possa ser desmembrado sem ser destruído. Mas, também, faz com que o corpo não possa mais existir, nem ser definido como "corpo próprio", pois ele perdeu a integridade de todos os seus membros. Ao nos reportarmos, então, ao corpo amputado, vemos concretizada essa possibilidade de desmembramento de uma de suas partes, onde, ao invés de ser destruído, ele ganha uma nova vida ao ser transformado.

Concomitantemente, ao perder a sua integridade, ao tornar-se um corpo incompleto, ele passa a existir e ser subjetivado por outros olhares sociais.

Muitos entrevistados mencionaram que o corpo amputado não era o corpo esperado ou desejado, mas ainda assim era o "seu corpo". Esta situação, inicialmente perturbadora, acabou sendo naturalizada com o passar do tempo, na medida em que se tornou habitual ostentar, sob o olhar do Outro, um corpo com formas diferentes: "Eu não me sinto complexada. Nada, nada, nada. Não tenho preconceito. Eu até estou me achando mais bonita e diferente, viu? Com a prótese. Até me apelidaram de mulher biônica. Eu estou contente, porque Van Gogh cortou a orelha, eu cortei a perna" (Corina, 79a).

Não aceitar que seus corpos foram modificados pela amputação significa viver no passado, num eterno luto pelo perdido, por um corpo que não existe mais. Para vários colaboradores da pesquisa, usar uma prótese externa fez com que resgatassem não apenas a funcionalidade corporal mas, ainda, parte de sua estética, na medida em que passaram a vislumbrar esse novo corpo novamente como completo. Assim, a aceitação da amputação passou, necessariamente, por um processo de "naturalização" desse outro corpo artificial, construído pela intervenção cirúrgica e pela sua reconstrução com o auxílio de um artefato tecnológico. Assim, na medida em que a prótese entra em contato com seus corpos, ela passa a ser incorporada a sua imagem corporal, tornando-se um prolongamento de seus corpos, hibridizando-se.

\title{
A imperfeição vista pelos outros
}

Com base nos depoimentos dos participantes, foi possível perceber que seus corpos modificados pela amputação causaram um estranhamento não somente para si, mas, sobretudo, para os outros ${ }^{4}$. Modificaram-se seus corpos e, junto com essa mudança, suas relações sociais também se alteraram. Tornar-se um amputado

\author{
Para Ortega (1999), o \\ cuidado de si é \\ inseparável da relação \\ com o outro. E, como \\ afirma Mèlich (1998), o \\ indivíduo é refém do \\ outro, sendo o outro \\ entendido como aquele \\ que transcende \\ infinitamente, aquele \\ que jamais o indivíduo \\ poderá possuir.
}


foi uma situação, muitas vezes, mais difícil de ser suportada diante do olhar inquisidor do outro do que de si mesmo.

Como afirma Kehl (2003), os corpos modificam-se por efeito do que se diz sobre eles e do novo lugar social que se produz, fazendo apelo a um modo diferenciado de estar "dentro da própria pele". Portanto, não ocorre somente uma mudança estética, pois a experiência do "eu" que se reconhece num corpo desvalorizado socialmente é totalmente diversa daquela vivenciada por quem se representa para as outras pessoas como tendo valor. Desta forma, um corpo investido de um novo discurso produz um novo "eu", na medida em que nossos corpos são dependentes da rede discursiva onde estão inseridos, como também são dependentes da rede de trocas que estabelecemos, ou seja, troca de olhares, de toques, de palavras e de substâncias.

Esta mudança na forma de ser olhado, a partir da amputação, provocou, em alguns participantes, o sentimento de ser outra pessoa: "Quando eu amputei, quando eu tava no hospital, eu pensei: Quando eu for para casa, como será que vai ser? As pessoas vão vir me visitar e vão me olhar como? Isso eu pensava" (Júlia, 49a).

Inicialmente, a amputação provocou, nos participantes, a sensação de se sentirem estrangeiros tanto diante de si como diante do outro, o qual passou a ser representado por quem possuía todas as funções e os movimentos corporais e relacionais preservados. Num instante, o indivíduo descobriu-se um cidadão de lugar nenhum, já que, após a amputação, em raras circunstâncias, ele passou a ser visto como "natural". A partir de então, os participantes passaram a conviver com situações que alteraram seus hábitos, saberes e práticas relacionais diárias, vida sexual, profissional, auto-estima, percepção da própria imagem, mobilidade real e simbólica, no espaço social, produtivo e doméstico.

Apesar de estarem cientes da enorme variedade que o ser humano pode apresentar no que diz respeito às características corporais, os participantes evidenciaram que as diferenças físicas passaram a ser vistas como marcas corporais que se sobressaem em relação a outras, pela impossibilidade de serem ocultadas e escondidas. Como afirma Gil (2002), o corpo foi feito para desaparecer, porém quando ele insiste em sua presença, quando dele o indivíduo não consegue se livrar, como ocorre, por exemplo, com a amputação, ele fica condenado a habitá-lo em sua alteridade.

Desta forma, sua visibilidade ocasionou, em algumas ocasiões, associações a condições patológicas, onde essas marcas corporais passaram a se configurar como estigmas, orientando a percepção do indivíduo, daquele que olha, a partir dessa característica física, que passa a ser considerada a principal, por ser a mais evidente. Nesse sentido, a amputação foi vista como algo que desacomoda, fazendo com que o indivíduo ganhe visibilidade, colocando seu corpo à mostra, testemunho de sua diferença. Ao indivíduo "normal" está reservado o privilégio de passear numa rua sem suscitar a menor indiscrição. Simultaneamente, o fato de ser olhado pelo outro, constitui-se, assim, numa chamada, num apelo irresistível, pois obriga o indivíduo e exige dele uma resposta (Le Breton, 2006; Ortega, 2002). Situação essa diferenciada para os participantes que, nos seus depoimentos, evidenciaram quanto esses olhares podiam ser perturbadores.

\begin{abstract}
Antes de amputar a minha perna, eu convivi muito pouco com pessoas amputadas [...] Só uma pessoa que eu conhecia que era amputado. Então, eu sempre olhei para ele como uma pessoa diferente. E é isso que eu sinto em relação a mim. Que as pessoas também me olham. Ó, essa ali é uma amputada, é diferente. Sabe, é um preconceito que eu acho que eu sempre imaginei que as pessoas têm. Talvez, porque eu sempre tive. (Júlia, 49a)
\end{abstract}

Eu me sinto estranho quando ninguém olha pra mim. Tem alguma coisa errada comigo! Ninguém olhou pra mim! Quando olham pra mim é normal. (Guilherme, 36a)

Esse olhar, inicialmente instigante, revelador de sua diferença corporal, com o passar do tempo, passou a causar menos impacto, permitindo que o indivíduo não se sentisse tão desconfortável com sua situação. Para os participantes o olhar temido era também aquele que emanava sinais de aceitação, permitindo que (re)significassem sua existência. 
Buscar ser reconhecido no olhar das outras pessoas, não somente como alguém que possui um corpo amputado, mas como alguém que vive, apesar de possuir um corpo imperfeito, fez com que os participantes procurassem o grupo de apoio realizado mensalmente na clínica onde foi desenvolvida a pesquisa. Nesses encontros, ouvindo os relatos dos presentes e assumindo o lugar de "quem olha", os participantes sentiam-se acolhidos pelos demais, pois além de compartilhar histórias de vidas marcadas pela amputação, também compartilhavam os mesmos sonhos de poder voltar a ficar de pé e andar após a colocação da prótese. Essas trocas intersubjetivas apareceram em alguns relatos, quando os participantes da pesquisa descreviam suas experiências no grupo de apoio.

O grupo tem uma importância fundamental pra mim. Porque eu não me sinto diferente dos outros. Ali todo mundo é igual a mim. Essa troca de experiências, isso foi uma coisa, assim, que a partir dali eu comecei a aceitar a minha amputação. Porque até então, eu não tava conseguindo. Então, o fato de eu ver que tem tanta gente na mesma situação que eu, me ajudou muito. (Júlia, 49a)

Eu fui vendo outras pessoas que tinham situações piores. Como é que conseguiam, né? Levar uma vida digna. Ser um ser humano apesar de tudo... Eu fui me acostumando com aquilo. Eu não olhava mais para o problema, quando eu conversava com as pessoas. Eu não olhava se a pessoa caminhava estranho ... eu via era a pessoa na minha frente. (Guilherme, 36a)

No grupo de apoio, a questão do sofrimento, em diferentes medidas, e de forma distinta, aproximou os participantes e os envolveu também, sendo que esses vínculos estabelecidos mostraram-se decisivos no processo de (re)significação dos seus corpos amputados. Na medida em que o reconhecimento do indivíduo passa pelo outro, por meio da negociação constitutiva da própria vida, ele vai e volta, exige e cede, dá e recebe, no espaço intervalar dos entre-lugares. Os indivíduos, então, em suas desditas e encontros, permitem-se desenraizar-se sem que ocorra uma total desidentificação (Guerra Neto, 2002). Nesse processo de renascer num corpo estranho, amputado, o indivíduo não está sozinho, pois diante dos olhares que recebe, torna-se "outro" tanto para si mesmo como para as pessoas ao seu redor, pois já não pode mais ser o mesmo num corpo que deixou de ser o "seu".

Assim, para os participantes, a passagem pela clínica significava estarem em um local onde sentiamse compreendidos, acolhidos e incluídos. Suas marcas corporais, que em outros locais eram interpretadas como sendo sinal de imperfeição, na clínica, passaram a ser vistas como uma característica de pertencimento e de identidade. Desta forma, as reuniões mensais do grupo de apoio, a fisioterapia e as intervenções do protesista constituíam-se como "ritos de passagem" para os participantes da pesquisa. Exercitando seus corpos, falando de suas dificuldades e de seus ganhos, olhando para os corpos dos outros pacientes, compartilhando suas histórias, preparando-se para a protetização, ou seja, toda essa gama de experiências corporais auxiliou no processo de familiarização de seus corpos amputados. Permitiram, portanto, aprender novamente a decifrar seus códigos corporais, subjetivá-los a partir do encontro com outros corpos, os quais apresentavam marcas semelhantes, enfim, tornar o corpo "estranho" em conhecido.

\section{O corpo protetizado: um outro de si mesmo}

Na sociedade contemporânea, a tecnologia é uma construção na qual o sujeito está profundamente envolvido. Como afirma Couto (2001), o ser humano inventou a técnica e por ela passou a ser inventado, ou seja, a artificialidade está presente desde a formação das primeiras sociedades. Por esta razão, não faz sentido algum separar o natural do artificial, o ser humano da técnica, uma vez que se constituem reciprocamente. Dotado de um caráter inacabado, em processualidade, o corpo humano permitiu que as tecnologias o invadissem, investindo-o, prolongando sua vida, e sua funcionalidade. Nessa perspectiva é possível afirmar que as tecnologias acoplaram-se aos corpos tais como as próteses, tornando-os mais potentes. 
Apesar dos aparatos técnicos atuarem de forma diferenciada, eles têm como função suprir uma deficiência, substituir uma falha, corrigir um desvio ou aumentar sua performance. Independentemente de serem externos e visíveis, ou internos e invisíveis, esses aparatos apresentam a característica em comum de serem objetos "estranhos" ao corpo humano e, por esta razão, precisam ser subjetivados, incorporados, tornados familiar, num processo de íntima convivência entre o humano e a máquina (Couto, 2000; Virilio, 1996). As próteses ortopédicas podem ser analisadas nesse sentido, visto que são observadas como equipamentos que têm a função de substituir o segmento ausente, integrando-se ao corpo, passando a ser um prolongamento, uma extensão de sua cartografia (Moreira, 2004).

Durante a pesquisa de campo, foi possível identificar que o processo de protetização era uma preocupação não apenas dos amputados, mas da equipe que atuava na clínica. Nas entrevistas realizadas, como a do fisioterapeuta e a do protesista, essa preocupação se mostrou latente pois estes profissionais preparavam o corpo do indivíduo para receber o artifício. Nos seus depoimentos, mencionaram, por diversas vezes, o caráter individual e provisório da prótese que, como o próprio corpo, está sempre em mutação. Segundo o protesista, seu papel é de "esculpir os corpos", pois suas mãos modelam a prótese que assumirá as características pessoais de cada paciente, tornando-se única e intransferível, cujo modelo depende tanto da disponibilidade econômica do usuário quanto dos seus desejos e intencionalidades: "A prótese é pessoal, foi confeccionada. Cada um é cada um. Nunca vai ser igual. Dá para fazer uma personalizada. A prótese jamais vai ser para vida inteira. Desde que nascemos, até partir, a característica anatômica vai mudando" (Protesista).

Já nos pacientes, a preocupação era de outra ordem. Nos primeiros contatos com a prótese, temiam o desconhecido, o nunca vivenciado, o objeto pouco usual visto, até então, como algo distante de si. Apesar de desejado, o uso da prótese traduzia-se em algo novo e desafiador. Todos estavam cientes de que a sensação nunca seria como a da perna "perdida", mas que o seu uso permitiria resgatar as funções, os valores e a estética, entre outros atributos perdidos com a amputação. As próteses assumiram o papel de acessórios versáteis que foram acoplados aos seus corpos, objetivando, mesmo que de forma provisória, solucionar a deficiência presente, podendo ser dispensada sempre que fosse desejado. Esta experiência mobilizou nos participantes inúmeras sensações.

Quando eu coloquei a prótese pela primeira vez, foi uma sensação, assim diferente. Eu disse: Não é minha perna, mas é uma substituta! (Roberto,70a)

Tu sabes que aquilo não nasceu com a gente. Quer dizer, uma coisa que está entrando no corpo da gente. Dali pra diante tem que ser aquilo [...] Mas, o corpo tem que se ajustar à prótese, principalmente a cabeça, que é quem leva o corpo. (Volnei, 63a)

Com base em seus depoimentos, foi possível perceber que, após a amputação, os participantes buscaram na tecnologia a possibilidade de resgatar aquilo que foi extirpado do seu corpo, não sendo somente a materialidade orgânica perdida, mas também o simbólico que foi retirado de sua vida, como, por exemplo, a "independência", a "autoridade" e a "felicidade". Tornar-se um usuário de prótese permitiu aos participantes resgatar a humanidade, a dignidade, a autonomia, a felicidade, a vaidade, entre outras maneiras de ser, perdidas com a amputação, na medida em que, com o seu uso, foi possível novamente: ficar de pé sem o auxílio de muletas, liberar as mãos e utilizá-las com outras finalidades além de servir como apoio, caminhar com autonomia, enfim, retomar algumas das práticas sociais e cotidianas que tinham sido impedidas de serem exercidas ou realizadas devido à amputação. Desta forma, podemos dizer que as limitações foram vistas, pelos participantes, como sendo algo temporário, e que o uso da prótese ofereceu outras possibilidades, talvez um porvir incerto, mas eles aceitaram o desafio de novamente transformar sua corporalidade e, junto com ela, construírem novas formas de habitá-la.

Tornar-se um usuário de prótese, significou, para os participantes desta pesquisa, deixar que o seu corpo entrasse em contato com outro corpo, transpusesse o seu limite corporal, sendo, portanto, invadido por vivências nunca experimentadas anteriormente. As próteses foram vistas como sendo 
"naturais", uma mixagem, onde a pele humana e a superfície sintética da prótese unificavam-se numa íntima convivência entre indivíduo e artefato, necessitando de cuidados, tais como substituições, ajustes periódicos, acoplagens e desacoplagens: "Eu acho que nós temos que fazer com que a prótese se encaixe com a gente. A prótese é um corpo estranho e ela fica fazendo parte do corpo. Então, a gente tem que trabalhar em harmonia com ela" (Júlia, 49a).

Dia a dia, a prótese passou a ocupar uma posição de destaque no cotidiano dos sujeitos investigados, deixando de ser identificada como um "objeto estranho", para assumir a função de um "acessório pessoal". De um modo geral, a prótese foi vista como algo útil, mas ao mesmo tempo um objeto estranho que estava "entrando em seus corpos". Precisavam, portanto, torná-la familiar, fazer dela uma parte de si. A adaptação à prótese foi narrada como uma experiência paradoxal, permeada de expectativas e receios, alegrias e tristezas, um (re)conhecimento de suas potencialidades, bem como de seus limites físicos, pois o corpo, de alguma forma, sinalizava que um outro corpo estava tentando acoplar-se a ele e reagia. A adaptação foi constituída por um duplo desafio, onde eles tiveram de (re)aprender a dominar seus corpos transformados pela amputação, e, simultaneamente, aprender algo novo, isto é, dominar um "corpo estranho", a prótese, com a qual dividiriam sua intimidade.

Da mesma forma, quando não a estavam usando, sentiam essa ausência como algo desagradável, como se seus corpos demandassem sua constante presença: "Quando eu estou com a prótese, eu tiro ela, eu sinto falta, sabe. Falta alguma coisa. Então, é como se fosse uma perna normal. Tu sentes falta daquilo" (Rogério, 18a).

Em face de este acoplamento, a prótese passou a ser percebida, por vários dos entrevistados, como um prolongamento dos seus corpos. Por esse motivo, em determinado momento, deixaram de ocultála, ainda que alguns deles relatassem certo incômodo com os olhares dos Outros:

Eu procuro não esconder. Eu acho que faz parte de mim. É como uma pessoa que usa anel, ali bonito, um óculos, um silicone. Eu sou assim! Quem convive comigo aprende a me aceitar do jeito que eu sou e vê que por trás da prótese tem um ser humano. (Guilherme, 36a)

Saia, não! Saia com prótese, não! É calça comprida. Eu nunca usava, assim, calça comprida.

Mas depois que eu amputei [...] eu pensei assim ó, uma calça comprida é melhor. (Paula, 65a)

Múltiplas foram as formas que cada um utilizou para mudar, atualizar-se e aceitar o desafio de se tornar um outro de si mesmo. Se o corpo protetizado devia estar ou não desvelado ao olhar alheio, veio a ser uma opção pessoal de compartilhar o fato de ter se tornado alguém com características corporais diferenciadas, ou de guardar para si o desafio de ter transgredido seus limites físicos e pessoais.

Nos relatos de alguns participantes ficava evidente a identificação que tinham construído de si a partir da mixagem entre seus corpos e a prótese.

Quando eu comecei a usar a prótese, eu me achava assim meio máquina. Eu tinha a sensação de ser um homem meio máquina. Eu me olhava no espelho, olhava aquele negócio metálico ali e era diferente. Eu tava me sentindo um robô. Mas depois, aquilo já foi fazendo parte de mim e eu fui me adaptando. E depois eu nem mais percebia que eu tinha prótese. (Guilherme, 36a)

Sou um homem biônico. Eu tenho um marca-passo, eu tenho a perna, qualquer dia um olho [...] Tem um netinho meu que já me chama de "vôcop". (Juliano,76a)

As próteses, para os seus usuários, acabaram transformando a imagem corporal que eles tinham de si mesmos. Além disso, seu uso proporcionou que vivenciassem uma situação de intimidade com um objeto externo ao seu corpo, o que não significou ter havido uma síntese do orgânico com o artificial, mas uma coexistência, uma interação entre esses elementos até então considerados incompatíveis. Como explicitou um dos participantes: "Eu sempre digo que a prótese é importante, mas mais importante é o ser humano que está em cima da prótese. A prótese é só um objeto, é um apoio. Se não tiver a prótese, o ser humano vai viver também" (Guilherme, 36a). 
Como afirma Couto (2001), as máquinas passam a ser vistas como componentes íntimos, ou seja, partes amigáveis dos indivíduos. Desta forma, a prótese passa a ocupar um lugar importante na vida dos participantes, compartilhando com eles momentos íntimos e sociais, atividades rotineiras, eventos especiais, enfim, deixa de ser somente um "objeto estranho", em alguns momentos incômodos, para tornar-se um "acessório pessoal".

Ao não se conformarem com a limitação funcional imposta pela amputação, os participantes dessa pesquisa buscaram, por meio da utilização de próteses, a superação da sua incompletude, fugindo da sua identificação como algo constituído e fixado na deficiência. Articulando-se com territórios de outra natureza, eles acabaram produzindo, a partir de sua imperfeição, de sua incompletude, formas variáveis de presença corporal, móveis e mutantes, refazendo-se a si mesmos, tendo como sua principal aliada a tecnologia, cujo acoplamento promoveu em si e nos seus corpos outras eficiências.

\section{Considerações finais}

Apesar de a vida humana transformar-se continuamente, sua finitude é insuperável, pois a lei da existência é a "impermanência", onde o indivíduo é o resultado tanto de ações premeditadas, quanto de causalidades. Neste sentido, a amputação adquirida de um segmento corporal mostra-se como um acontecimento que rompe com a linearidade do tempo histórico, do esperado, do que seria o natural no processo de viver e envelhecer (Guerra Neto, 2002; Pombo, 2002; Vilela, 2001).

O corpo amputado foge de possíveis enquadramentos, confirmando e explicitando a diferença, caráter indisfarçável de eterno estrangeiro aos olhos dos outros (Kristeva, 1994). No entanto, a subjetividade não se esgota num único modelo de corpo, mesmo que saibamos que existe um modelo preconizado pela sociedade que seja sinônimo de saúde e beleza. No entanto, para os participantes deste estudo, mesmo tendo corpos que fujam de um possível enquadramento no modelo corporal preponderante, a alteridade instalada pela amputação, ao mesmo tempo biológica e simbólica, torna-se parte do mesmo indivíduo (Tucherman, 1999).

No presente estudo, os indivíduos que realizaram a amputação de um segmento corporal reescreveram sua história e reinventaram suas vidas, reportando-se a dois momentos distintos de existência, ou seja, antes e depois da amputação. Marcados em suas corporalidades pela ausência de uma parte de si, ressignificaram suas vidas a partir do olhar de si e das outras pessoas. Ao transpor a limitação física presente, não se fixando numa posição de "impedido" de continuar vivendo, o indivíduo possibilita à subjetividade existir em territórios existenciais em construção, como o corpo protetizado.

A fusão entre a carne e o artefato é uma forma recorrente de potencializar os usos do corpo que, por ser dotado de um caráter inacabado, necessita dessa mixagem, dado que somente a sua natureza biológica já não pode lhe garantir (Couto, 2000). Portanto, o ser humano pode ser vislumbrado tanto como um produtor de artefatos, ou ele próprio vir a ser o artifício, pois, ao mesmo tempo em que inventou a técnica, por ela passou a ser inventado. Sob este prisma, o corpo é um objeto ininterruptamente em elaboração, e, por esta razão, o uso da prótese permitiu, aos indivíduos participantes do estudo que realizaram uma amputação, reelaborar sua corporalidade (Couto, 2000; Bourg, 1996).

As narrativas permitem pensar que o corpo "natural" não pode ser assumido como um destino, como algo imutável. Ele é constantemente fabricado e moldado, não somente pelas suas vivências, mas também pelas intervenções de várias ordens que nele se podem operar. Neste estudo, os corpos amputados deixaram de ser "incompletos", para se tornarem corpos performáticos ao serem protetizados. Os participantes reinventaram suas vidas e conseguiram "renascer" com o auxílio das tecnologias. Assim como muitos dos eventos que marcam mudanças biológicas ou sociais em nossas vidas, foi possível compreender que a passagem de um modo de vida "naturalmente" humano, anterior à amputação, para tornarem-se "artificialmente" produzidas pela protetização, significou para essas pessoas um rito de passagem. Nesse processo, deixaram de se observar somente como portadores de corpos imperfeitos, para tornarem-se completos, protetizados, e, mesmo com esse acoplamento, humanos. 


\section{Referências}

BARDIN, L. Análise de conteúdo. Lisboa: Persona Edições, 1977.

BOURG, D. O homem artifício: o sentido da técnica. Lisboa: Instituto Piaget, 1996.

CANGUILHEM, G. O normal e o patológico. Rio de Janeiro: Forense Universitária, 2000.

COUTO, E. Corpos modificados: o saudável e o doente na cibercultura. In: LOURO, G.; NECKEL, J.; GOELLNER, S. (Orgs.). Corpo, gênero e sexualidade: um debate contemporâneo na educação. Petrópolis: Vozes, 2003. p.172-86.

Estética corporal e protecionismo técnico nas culturas higienista e desportiva. In: GRANDO, J.C. (Org.). A (des)construção do corpo. Blumenau: Edifurb, 2001. p.35-59.

O homem satélite: estética e mutações do corpo na sociedade tecnológica. Ijuí: Editora Unijuí, 2000.

GIL, J. O corpo paradoxal. In: LINS, D.; GADELHA, S. (Orgs.). Nietzsche e Deleuze: que pode o corpo. Rio de Janeiro: Relume Dumará, 2002. p.93-110.

GUERRA NETO, A. Corpo e sofrimento: Buda, Dionísio e Niestzsche. In: LINS, D.; GADELHA, S. (Eds.). Niestzsche e Deleuze: o que pode o corpo. Rio de Janeiro: Relume Dumará, 2002. p.13-36.

JOHNSON, R. O que é, afinal, Estudos Culturais? In: SILVA, T.T. (Org.). O que é, afinal, Estudos Culturais? Belo Horizonte: Autêntica, 1999. p.3-29.

KEHL, M.R. As máquinas falantes. In: NOVAES, A. (Org.). O homem-máquina: a ciência manipula o corpo. São Paulo: Companhia das Letras, 2003. p.243-60.

KRISTEVA, J. Estrangeiro para nós mesmos. Rio de Janeiro: Rocco, 1994.

LE BRETON, D. A síndrome de frankenstein. In: SANT'ANNA, D.B. (Org.). Políticas do corpo. São Paulo: Estação Liberdade,1995.

A sociologia do corpo. Petrópolis: Vozes, 2006.

LUCCIA, N. et al. Amputações de membros. In: GOFFI, F. et al. (Orgs.). Técnica cirúrgica: bases anatômicas, fisiopatológicas e técnicas cirúrgicas. São Paulo: Atheneu, 2001. p.180-99.

MÈLICH, J-C. A palavra múltipla: por uma educação (po)ética. In: LARROSA, J.; SKLIAR, C. (Orgs.). Habitantes de Babel: políticas e poéticas da diferença. Belo Horizonte: Autêntica, 2001. p.269-80.

MOREIRA, I. Próteses e especulações arquitetônicas (ou nós ainda não estamos completos). Barcelona, 2004. Disponível em: <http://www.vitruvius.com.br/ arquitextos/arq040/arq040_01.asp>. Acesso em: 23 jan. 2007.

OMOTE, S. Deficiência e não-deficiência: recortes do mesmo tecido. Rev. Bras. Educ. Esp., v.1, n.2, p.65-71, 1997.

ORTEGA, F. Da ascese à bio-ascese ou do corpo submetido à submissão ao corpo. In: RAGO, M. ORLANDI, L.; VEIGA-NETO, A. (Orgs.). Imagens de Foucault e Deleuze: ressonâncias nietzschianas. Rio de Janeiro: DP\&A, 2002. p.139-70.

O si mesmo e os outros: intersubjetividade e constituição do sujeito. In: p.123-43.

Amizade e estética da existência em Foucault. Rio de Janeiro: Graal, 1999.

PINHEIRO, O. Entrevista: uma prática discursiva. In: SPINK, M.J. (Org.). Práticas discursivas e produção de sentidos no cotidiano: aproximações teóricas e metodológicas. São Paulo: Cortez, 2000. p.52-74. 
POMBO, C. O corpo da estética: arte e natureza em Gilles Deleuze. In: LINS, D.; GADELHA, S. (Eds.). Nietzsche e Deleuze: o que pode o corpo. Rio de Janeiro: Relume Dumará, 2002. p.37-48.

SANT'ANNA, D.B. Corpos de passagem: ensaios sobre a subjetividade contemporânea. São Paulo: Estação Liberdade, 2001.

SFEZ, L. A saúde perfeita: crítica de uma nova utopia. São Paulo: Edições Loyola, 1996.

SPINK, M.J. A pesquisa como prática discursiva: superando os horrores metodológicos. In: . (Org.) Práticas discursivas e produção de sentidos no cotidiano:

aproximações teóricas e metodológicas. São Paulo: Cortez, 2000. p.10-25.

TUCHERMAN, I. Breve história do corpo e de seus monstros. Lisboa: Passagens, 1999.

VILELA, E. Corpos inabitáveis: errância, filosofia e memória. In: LARROSA, J.; SKLIAR, C. (Eds.). Habitantes de Babel: políticas e poéticas da diferença. Belo Horizonte: Autêntica, 2001. p.233-54.

VILLAÇA, N. Em nome do corpo. Rio de Janeiro: Rocco, 1998.

VIRILIO, P. A arte do motor. São Paulo: Estação Liberdade, 1996.

PAIVA, L.L.; GOELLNER, S.V. Re-inventando la vida: un estudio cualitativo sobre los significados culturales atribuidos a la reconstrucción corporal de amputados mediante prótesis. Interface - Comunic., Saúde, Educ., v.12, n.26, p.485-97, jul./set. 2008.

Se analizan los significados culturales que los individuos amputados atribuyen a sus cuerpos y a sus vidas cotidianas tras el uso de prótesis. Se utilizaron como presupuestos teóricos los estudios culturales y socio-históricos sobre el cuerpo humano. Participaron de la pesquisa nueve pacientes, siendo seis hombres y tres mujeres, con edades variando de 18 a 82 años, además del protésico y del fisioterapeuta. Las entrevistas se analizaron por medio de la técnica de análisis de contenido, identificándose cuatro categorías temáticas: "Tornarse otro: el cuerpo amputado"; "Familiarizarse con otro cuerpo"; "La imperfección vista por los otros" y "El cuerpo en prótesis: otro de sí mismo". El análisis por categorías reveló que la prótesis se observó como una forma de rescatar la función perdida y también la estética corporal en la medida en que los pacientes han visto sus cuerpos nuevamente como completos. El uso de la prótesis ha significado una forma de mantenerse humano aunque sustentado por un objeto artificial.

Palabras clave: Amputados. Miembros artificiales. Reconstrucción corporal. 